\title{
Fracture Resistance of Simulated External Cervical Resorption in Anterior Teeth Restored with and without a Fiber Post.
}

\author{
Michelle M. Romeo \\ West Virginia University, mromeo2@mix.wvu.edu
}

Follow this and additional works at: https://researchrepository.wvu.edu/etd

Part of the Endodontics and Endodontology Commons

\footnotetext{
Recommended Citation

Romeo, Michelle M., "Fracture Resistance of Simulated External Cervical Resorption in Anterior Teeth Restored with and without a Fiber Post." (2020). Graduate Theses, Dissertations, and Problem Reports. 7964.

https://researchrepository.wvu.edu/etd/7964

This Thesis is protected by copyright and/or related rights. It has been brought to you by the The Research Repository @ WVU with permission from the rights-holder(s). You are free to use this Thesis in any way that is permitted by the copyright and related rights legislation that applies to your use. For other uses you must obtain permission from the rights-holder(s) directly, unless additional rights are indicated by a Creative Commons license in the record and/ or on the work itself. This Thesis has been accepted for inclusion in WVU Graduate Theses, Dissertations, and Problem Reports collection by an authorized administrator of The Research Repository @ WVU. For more information, please contact researchrepository@mail.wvu.edu.
} 
Fracture Resistance of Simulated External Cervical Resorption in Anterior Teeth Restored with and without a Fiber Post.

Michelle Romeo, D.D.S.

Thesis submitted to the School of Dentistry at West Virginia University in partial fulfillment of the requirements for the degree of

Master of Science in Endodontics

Samuel Dorn, D.D.S.

Mark Byron, D.D.S., M.S.

Susan Morgan, D.D.S., MAGD

Department of Endodontics

Morgantown, WV

2020

Keywords: Endodontics, external cervical resorption, fracture resistance, fiber post, resorption, repair

Copyright 2020 Michelle Romeo, D.D.S. 


\begin{abstract}
$\underline{\text { Abstract }}$
Fracture Resistance of Simulated External Cervical Resorption in Anterior Teeth Restored with and without a Fiber Post.

Michelle Romeo, D.D.S.
\end{abstract}

Introduction: External cervical resorption (ECR) is a destructive type of external resorption that can be difficult to treat. ECR usually begins subgingival at the cementoenamel junction of teeth and continues apically and circumferentially. This substantial loss of tooth structure may make these teeth more prone to fracture and should be addressed when treatment planning teeth with ECR. The aim of this in vitro study was to evaluate the fracture resistance of treated and nontreated teeth with simulated ECR using two different treatment modalities.

Materials and Methods: Forty-eight extracted human permanent mandibular central incisors were selected. Teeth were randomly divided into four groups $(n=12)$. Twelve teeth were assigned to the negative control no treatment group and the remaining 36 samples received standardized ECR cavities. Twelve of the teeth were not instrumented and were assigned as a positive control group. The remaining twenty-four teeth were instrumented and divided into two separate treatment modalities, a fiber post group and a gutta percha group. ECR cavities in the fiber post and gutta percha group were restored with a resin-modified glass ionomer material. Specimens were embedded in acrylic resin and subjected to fracture testing using a universal testing machine. The load $(\mathrm{N})$ at failure was recorded for each specimen, and the data was statistically analyzed.

Results: The negative control group had the highest fracture resistance and differed significantly from the positive control, fiber post, and gutta percha group $(P<0.05)$. No significant difference was found between the positive control, fiber post, or gutta percha group $(P>0.05)$.

Conclusion: This in-vitro study concluded that teeth with simulated ECR were found to have a decreased resistance to fracture, which suggests they are weaker and more prone to fracture. When restoring teeth with ECR, the placement of a fiber post is not necessary, as it will not increase their fracture resistance. 


\section{Dedication}

To my parents, Michael and Kathie, for encouraging me to journey through life never being afraid to accomplish many goals and for teaching me that there is no such thing as good enough. You instilled a strong work ethic in me from an early age by watching how hard you both worked to provide for our family. To my selfless husband, Andrew, for being by my side without a hint of hesitation as I first entered the military and then again as I chose to go back to school to specialize at the expense of us being long distance for 7 years. I will forever appreciate your endless support for me and my career. We have waited for this next chapter of our lives for a long time and I'm thrilled it's finally here. 


\section{Acknowledgements}

Dr. Sam Dorn, thank you for entering "retirement" and accepting Chair of WVU's Endodontic Department. From the day you set foot at WVU you have worked tirelessly to improve our residency and have been such a great asset to our program. I appreciate you pushing us to learn and do more each day.

Dr. Mark Byron, your love for teaching, compassion, and patience inspire me daily. We are very lucky to have you as program director and mentor. Thank you for all the long days, nights, and weekends that you have worked to make our program the best it can be.

Dr. Susan Morgan, thank you for getting me through dental school as my team leader and being so kind to support me again through residency by being on my thesis committee. The dental school is lucky to have such a caring and encouraging faculty member.

Vince Kish, I could have never completed this thesis without you. You were my logistics officer and I want to thank you for your expertise and time.

Chris Waters, thank you for the monthly pep talks that included pushing me to get my thesis completed and for the research resources you guided and provided me with.

Dr. Constance Wiener, my results could not have been completed without you. Thank you for taking the time and guiding me through SPSS.

Dr. Tom Borgia, your enthusiasm and passion for teaching made a lasting impact on my career. I will be forever grateful as you encouraged me to return to WVU and accepted me as a resident.

Drs. James Poulos, Mehran Malakpour, and Daniel Brawley, I was very fortunate to get to call each of you my co-residents. We encouraged, challenged, and learned from each other each day. Thank you for making residency such a great experience. 


\section{Table of Contents}

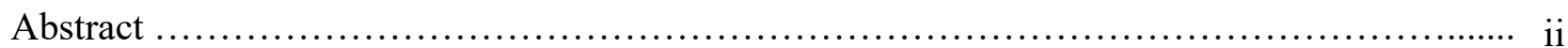

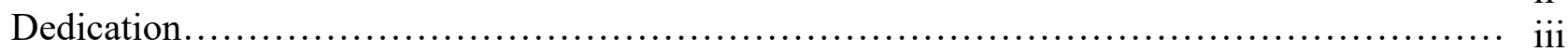

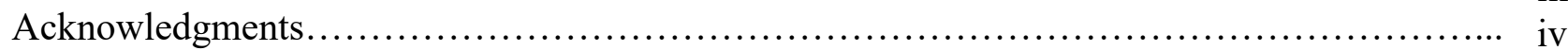

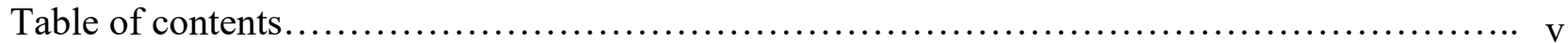

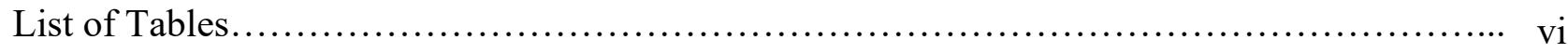

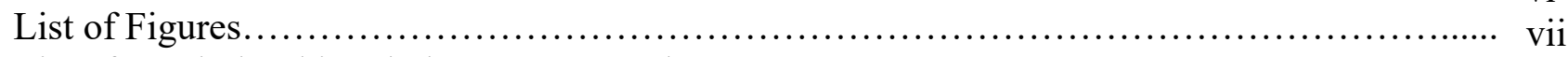

List of Symbols, abbreviations or nomenclature..................................... viii

Chapter I

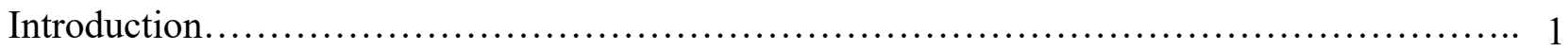

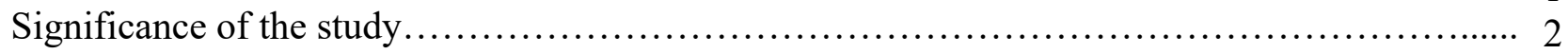

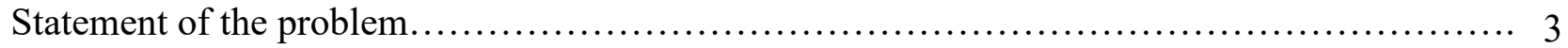

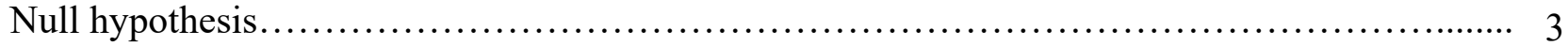

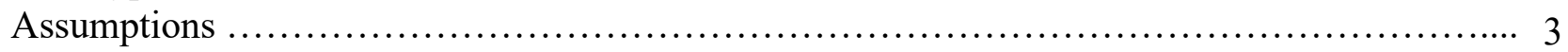

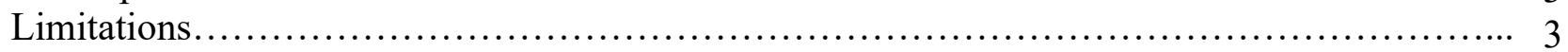

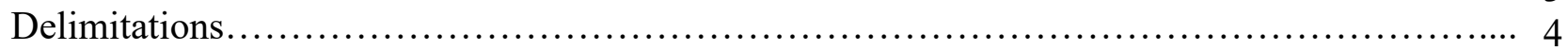

Chapter II

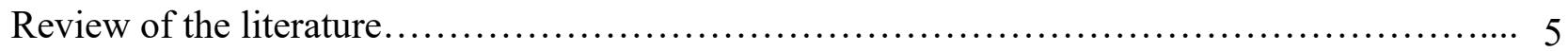

\section{Chapter III}

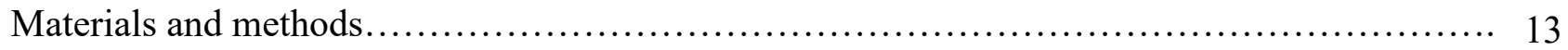

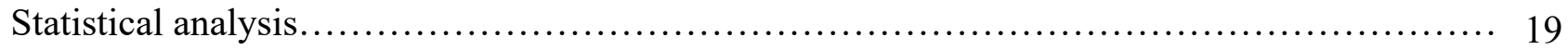

\section{Chapter IV}

Results..................................................................... 20

Discussion................................................................... 25

Chapter V

Conclusions................................................................. 28

Works Cited................................................................. 29

Appendix

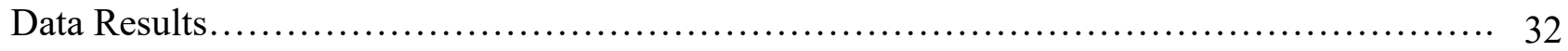




\section{List of Tables}

Table 1. Mean fracture resistance and standard deviation values of experimental groups......... 21

Table 2. Statistically significant results of multiple comparisons between groups.............. 22 


\section{List of Figures}

Figure 1. Samples radiographed to examine for defects............................. 13

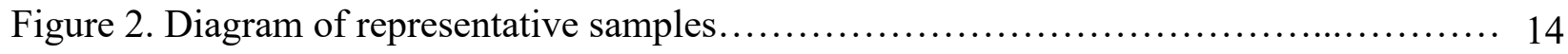

Figure 3. Mounting device used to hold specimen for access, instrumentation, and

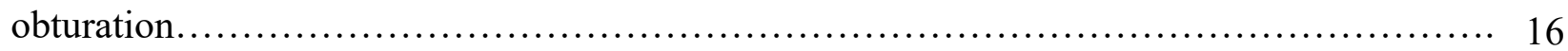

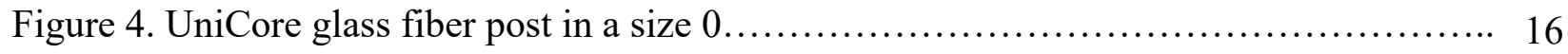

Figure 5. Specimen from Group 2, PC, with non-restored ECR cavity mounted in acrylic..... 17

Figure 6. Radiographs of representative sample................................... 17

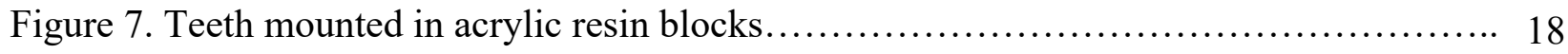

Figure 8. Instron machine with specimen mounted and ready for testing $\ldots \ldots \ldots \ldots \ldots \ldots \ldots \ldots$

Figure 9. Comparison of mean fracture resistance $(\mathrm{N})$ of the experimental groups........... 21

Figure 10. Specimen from Group 1 presenting with a fracture at the coronal third of the root... 22

Figure 11. Group 2 specimen presenting with a fracture at the inferior portion of the ECR

cavity

Figure 12. Group 3 specimen presenting with an oblique fracture at the apical portion of the

Fiber post....

Figure 13. Group 4 specimen presenting with a fracture inferior to the ECR repair. 


\section{List of Symbols, Abbreviations or Nomenclature}

Cementoenamel junction - CEJ

External cervical resorption - ECR

Invasive cervical resorption - ICR

Millimeters - mm

Newton - N

Periodontal ligament - PDL

Sodium hypochlorite - $\mathrm{NaOCl}$

Working length - WL 


\section{Chapter I}

\section{Introduction}

External cervical resorption (ECR), also known as invasive cervical resorption (ICR), is a complex type of resorption that involves dental, periodontal, and pulpal tissues (1). ECR begins at a portal of entry, typically located below the gingival epithelial attachment of the root and continues apically (1). The subgingival location of the lesion in the root causes ECR to go undetected intraorally and, as a result, must be discovered radiographically. Therefore, these lesions are commonly misdiagnosed and difficult to treat (2). Frequently, ECR is missed until the tooth becomes symptomatic and presents with extensive loss of tooth structure.

Treatment of teeth with ECR includes repair of the resorption cavity, and root canal therapy when the resorption extends into the tooth's pulp space. An additional consideration when treatment planning for cases with ECR is the tooth's predisposition to fracture due to the amount of tooth structure lost. Previous studies have found that loss of dentin compromises the mechanical integrity of the remaining tooth structure and can result in tooth fracture $(3,4)$. Frequently, root fractures have been found to occur in the cervical third of the root due to the presence of thin dentinal walls. Thin dentinal walls are an especially common finding in immature teeth. For example, Cvek found the incidence of root fracture in immature teeth to be between 28\% and 77\% (5). Most teeth with ECR are missing tooth structure mainly in the root and the cervical third. To determine the prognosis of treated teeth with ECR, it is important to study if this missing tooth structure predisposes the tooth to fracture.

To decrease the chances of fracture, previous studies have focused on ways to increase fracture resistance in teeth with missing tooth structure. Although teeth that have been heavily restored have been recorded to be more susceptible to fractures (6), to date, fracture resistance in 
teeth with ECR has not been studied. The existing research that looks at fracture resistance has been confined to teeth with immature root formation, internal root resorption, and compromised coronal tooth structure. The substantial tooth structure lost in ECR is in a location that differs from each of the formerly listed groups. One treatment modality that has been studied to alter a tooth's fracture resistance is intraradicular enforcement through post placement. Although post placement has been greatly debated in the literature, researchers unambiguously agree that dentists should evaluate if post placement could be beneficial based on the amount of coronal tooth structure lost (7). This statement does not pertain to teeth with ECR, since ECR lesions result in mostly radicular tooth structure lost. The research is lacking if post placement would benefit teeth with ECR.

The aim of this study is to evaluate the fracture resistance of non-treated teeth with ECR and treated teeth with ECR. Two treatment modalities were used to test for an increase in fracture resistance. This in vitro study was designed to help guide a clinician when restoring teeth with ECR.

\section{Significance of the study}

Tooth fracture is a significant problem in endodontically treated teeth $(3,4)$. Not only is tooth fracture often difficult to diagnose, but the prognosis of a vertical root fracture is unfavorable. Studies have shown that the leading cause of tooth fracture is the loss of tooth structure $(3,8)$. The amount of tooth structure lost from ECR and completion of root canal therapy make teeth with ECR possibly vulnerable to fracture. This study seeks to determine if teeth with ECR are more prone to fracture and if two different methods of restoring these teeth change the fracture resistance. Additionally, the study investigates the location where the tooth 
tends to fracture when it is obturated with different modalities and when it is unrestored. The findings of this study may aid in developing a protocol for treating teeth with ECR.

\section{Statement of the problem}

There is currently no treatment regimen for teeth presenting with ECR. Before developing a treatment protocol, fracture resistance in treated and non-treated teeth with ECR needs to be studied to understand the potential risk of tooth fracture. Are teeth with ECR more prone to fracture? Will the placement of a post in teeth with ECR change their fracture resistance?

\section{Null hypothesis}

The purpose of this in vitro study is to evaluate the fracture resistance in anterior teeth with simulated external cervical resorption restored with and without a fiber post. The null hypothesis is that the placement of a post will have no effect on fracture resistance in teeth with simulated external cervical resorption.

\section{Assumptions}

1. The Instron machine accurately demonstrates fracture resistance.

2. The simulated ECR cavity made by the operator is representative of a biologic ECR lesion.

\section{Limitations}

1. There are natural biologic differences associated with each tooth from different dentitions. 
2. The teeth were extracted and stored for differing lengths of time.

3. The in-vitro environment is different than that in the oral cavity.

\section{Delimitations}

1. Samples were limited to mandibular central incisors free of any cracks, carious lesions, or restorations.

2. The teeth were measured using a digital caliper and any teeth measuring more than $25 \%$ from the mean dimension value in relation to length, mesiodistal width, and buccolingual width, were excluded.

3. All endodontic and restorative treatment was completed by the same clinician to ensure consistency.

4. The specimens were stored in saline during the completion of the study.

5. The Instron probe was positioned at the same location in all specimens. 


\section{Chapter II}

\section{Review of literature}

\section{Predisposing factors}

\section{Histopathology}

\section{Clinical and radiographic presentation}

\section{Treatment and management of ECR}

\section{Fracture resistance and post placement}

\section{Post design}

Heithersay was the first to report the aggressive nature of external cervical resorption in 1999 and termed the process invasive cervical resorption $(9,10)$. A review of the available literature following Dr. Heithersay's initial publication reveals mostly case reports and case series. The focus of a majority of the research has been on the predisposing factors, histopathology, and radiographic presentation of ECR. The only publications that have focused on treatment and management of ECR have been case reports.

\section{Predisposing factors}

The etiology of ECR remains uncertain and is believed to be multifactorial. To find out why some teeth and not others are exhibiting ECR, researchers have focused on investigating predisposing factors of teeth that present with ECR. Heithersay laid the foundation for understanding ECR and was the first to study predisposing factors. In one of his first publications he analyzed 257 teeth that displayed ECR and found the highest potential predisposing factors to be orthodontic treatment, traumatic injury, internal bleaching, surgery, and restorative treatment (11). Mavridou et al. added parafunctional habits, poor oral health, malocclusion, and extraction of a neighboring tooth to the list of highest potential predisposing factors contributing to ECR by 
examining 337 cases of ECR. Out of the 337 teeth with ECR, 72\% were maxillary teeth (12).

Both Mavridou et al. and Heithersay found maxillary anterior teeth followed by mandibular molars to be the most frequent teeth affected by ECR. They also both documented multiple predisposing factors per tooth proposing that ECR is multifactorial $(11,12)$. In a study published in 2009, Von Arx et al.(13) suggested a transmission of feline virus to humans can result in multiple ECR lesions. In this study, they collected blood samples from four patients with multiple cervical resorption lesions and tested for feline herpes virus type-1 (FeHV-1). Two out of the four were found to have neutralizing antibodies against FeHV-1 and those two patients owned cats.

\section{Histopathology}

The histopathology of ECR has been studied by examining extracted teeth with ECR using nano-CT scanning and SEM technology. Mavridou et al. characterized the mechanism of ECR into three stages: the initiation stage, the resorption stage, and the repair stage. At the initiation phase, ECR begins at the portal of entry, an isolated area on the external root surface of dentin. The portal of entry is located inferior to the gingival epithelial attachment (1).

Destruction or absence of the cementum and periodontal ligament (PDL), along with the presence of an inflammatory stimulus are necessary for the resorptive process to begin (14). The absence of cementum, exposes dentin at the cementoenamel junction and creates an environment vulnerable to resorption (15). This allows macrophages to migrate into the site of injury and play a role in wound debridement and the formation of granulation tissue (1). In the resorption stage, resorptive lesions advance towards the pulp and away from the portal of entry in all planes, destroying cementum, dentin, and enamel. Located in the resorption lacunae are resorption (clastic) cells identified as osteoclast-like multinucleated cells. Throughout the reparative stage, 
osteoblast-like cells replace the resorbed tissue with the formation of mineralized bone-like tissue. During this stage both resorption and repair occur simultaneously at different sites of the tooth $(1,16)$.

\section{Clinical and radiographic presentation}

ECR is often misdiagnosed for internal resorption and caries (17). In many cases ECR goes undetected until the advanced stages when symptoms arise, or the radiographic presentation is more evident (1). The clinical presentation can look similar to a cervical carious lesion or the tooth can take on a pinkish discoloration due to the invasion of the granulation tissue $(10,16)$. The radiographic appearance of ECR ranges from well delineated radiolucencies to poorly defined lesions with irregular margins $(2,18)$. Heithersay developed a clinical classification to categorize ECR according to its extension into dentin and location into the root. Heithersay Class I and II lesions are localized and have no or little penetration into radicular dentin while Heithersay Class III invades dentin in the coronal third of the root and Heithersay Class IV extends beyond the coronal third of the root (10). The Heithersay classification is based on twodimensional imaging and is limited in classifying the true extent of the lesion. Patel proposed a three-dimensional classification in 2018 that uses periapical radiographs and cone beam computed tomography (CBCT) (16).

Taking a CBCT scan of teeth with ECR was supported when the American Association of Endodontists and the American Academy of Oral and Maxillofacial Radiologists released a joint position statement for the use of CBCT in endodontics in 2015 which listed recommendation 12 as: limited field of view CBCT is the imaging modality of choice in the localization and differentiation of external and internal resorption defects and the determination of appropriate treatment and prognosis (19). 


\section{Treatment and management of ECR}

The treatment of teeth with ECR includes accessing and removing the resorptive lesion, root canal therapy if needed, and repair of the resorption lesion. There currently is no standard protocol for the treatment of ECR and the publications that pertain to the treatment of ECR are case reports.

Heithersay (20) was the first to propose a treatment regimen for ECR in which the resorption lesion was mechanically debrided followed by a chemical treatment of $90 \%$ trichloroacetic acid (TCA) to cauterize the remaining resorption channels. Heithersay believed the TCA would achieve coagulation necrosis of deep inaccessible resorption channels. Schwartz (2) recommended opening up the dentin tubules with a bur after TCA application to compensate for TCA eliminating the hydroxyapatite at the dentin surface and allow for suitable bonding. The second step in treatment after removing the ECR lesion is to complete non-surgical root canal treatment if the resorption reaches the pulpal tissue. After completing the root canal therapy and repairing the endodontic access, restoring the resorptive defect using a glass ionomer material that would bond to the weakened tooth structure is recommended $(2,20)$. Resin-modified glass ionomer has been found to be biologically suitable to place at the subgingival location by numerous authors. An in-vitro study conducted by Gupta et al. observed periodontal fibroblast cells adhere and proliferate on resin-modified glass ionomer (21). Martins et al. restored subgingival root cavities in dogs using Fuji II resin-modified glass ionomer cement (GC Fuji II, GC America) and composite resin. They found both restorative materials to be biocompatible with an apical migration of epithelial cells onto the restorative materials (22).

Due to the subgingival location of the resorption lesion, one of the most complex aspects in treating teeth with ECR is accessibility of the resorption lesion. Surgical exposure, intentional 
replantation, orthodontic extrusion, and internal repair of the lesion are all methods of achieving access that have been recommended in case reports. Choosing which method to use to access the lesion greatly depends on the location and the extent of the lesion. Schwartz et al. reported on three cases of ECR that were treated and utilized two surgical and one internal approach based on the size and location of each lesion (2). A more recent case series treated teeth with asymptomatic ECR using an internal approach and vital pulp therapy (23).

Another suitable option for the treatment of ECR when the resorption has progressed to a Heithersay Class IV lesion is no treatment. A tooth with ECR may go several years without becoming symptomatic. Although the progression rate of ECR is unknown and has yet to be studied, Schwartz et al (2) recommended immediate treatment of any lesion that could be accessed before it progresses further to reduce the chances of the resorption advancing to a nontreatable stage.

\section{Fracture resistance and post placement}

Tooth fracture is the third leading cause of tooth loss, making tooth fracture a major concern in the field of dentistry (3). It was originally thought that endodontically treated teeth were brittle and more prone to fracture compared to vital teeth, but this belief was later questioned by several classic studies $(24,25)$. One of these studies, by Sedgley and Messer, compared the biomechanical and physical properties of dentin in endodontically treated teeth to vital teeth and found that their properties were similar (26). It was discovered that loss of missing tooth structure is the greatest contributing factor associated with endodontically treated teeth being more prone to fracture $(3,8)$. Reeh et al. (8) found that an MOD cavity preparation and loss of a marginal ridge greatly reduced a tooth's strength. 
The common finding of fractured endodontically treated teeth has led researchers to focus on ways to increase fracture resistance of teeth, with the expectation that increasing fracture resistance will decrease the chances of a tooth fracturing. The most highly used method to test fracture resistance is in a laboratory setting using a universal testing machine to measure the maximum load at which teeth fracture. By using this laboratory method of measuring fracture resistance of teeth, different treatment modalities to restore endodontically treated teeth can be studied. One treatment modality that some researchers recommend to increase fracture resistance is the placement of a post.

Post placement has been greatly debated in the literature. Akkayan and Gulmex reported that with the placement of a fiber post, the fracture resistance increased and the mode of fracture was repairable (27). Seto et al. found that using either a dual cure composite or a quartz fiber post with composite resin to a depth of $3 \mathrm{~mm}$ increased fracture resistance in simulated immature anterior teeth (28). Soares et al. observed a reduced incidence of catastrophic failures in teeth restored using a glass fiber post with an adhesive resin (29). Ferrari et al. (30) studied premolars that needed endodontic treatment and found a significant reduction in failure risk in the premolars that received a fiber post compared to those that did not.

In contrast to the studies recommending post placement, the literature is full of studies that report post placement does not increase fracture resistance. Guzy and Nicholls (31) found that cementing a metal post in anterior teeth did not reinforce the root. Fokkinga et al. concluded that posts are not necessarily required due to the findings that direct resin composite crowns with and without posts had similar fracture resistance and failure modes (32). A post study using endodontically treated maxillary incisors with class III composite restorations found that there 
was no advantage in fracture resistance when posts were placed and that post placement resulted in a catastrophic failure (33).

Although post placement to increase fracture resistance is heavily debated, the placement of a post to retain the restoration when a tooth has suffered extensive loss of tooth structure, is not (34). Clinicians are taught to determine whether a post is needed by the amount of remaining coronal tooth structure (25). When assessing loss of tooth structure, the majority of studies focus on coronal loss of tooth structure, not radicular tooth structure loss as ECR causes $(29,35,36)$.

The studies that evaluate fracture resistance when there is loss of radicular tooth structure pertain to thin dentinal walls or an immature apex $(5,37,38)$.

\section{Post design}

The material and design of posts have changed over the years as new materials have come onto the market and studies have emerged that favor one post design over another. Posts can be classified as active or passive, tapered or parallel, by material, and according to their diameter. Active posts, also called screw posts, are threaded to engage the dentin wall. Although active posts were thought to offer enhanced retention, this comes at the expense of the root as increased stresses within the root are introduced. Active posts are no longer recommended due to their increased potential for root fracture (39). Instead of engaging the wall and risking unfavorable stresses, passive posts rely on cementation adhesives for their retention. Passive posts can be tapered or parallel, but the use of parallel posts is more commonly favored due to the reports of parallel posts being more retentive and less likely to cause root fractures. Posts were originally fabricated using metals, but as more translucent ceramic crowns evolved, esthetics became a problem in the anterior zone. Ceramic, zirconia, and fiber posts were fabricated to combat this esthetic concern, however ceramic and zirconia post materials were 
found to have unfavorable properties. Both materials are weaker compared to metal, and therefore require a thicker post and more tooth structure removal to seat the post (25). Fiber posts on the other hand have many favorable properties including being able to bond to dentin, retrievability, and conservation of tooth structure. Fiber posts have a similar modulus of elasticity to dentin and have been reported to distribute stresses in the tooth more evenly, resulting in less root fractures (34). Manufacturing companies of posts offer a variety of post diameters and matching post space drills. It has been found that increasing the diameter of the post does not increase retention if post space is created by removing dentin. Given that the less tooth structure removed enhances the fracture resistance of endodontically restored teeth, the diameter of a post should be the smallest diameter possible and reflect the original size of the canal space (34).

For the reasons previously discussed this study chose to utilize a passive glass fiber post with the smallest diameter to test fracture resistance in mandibular anterior teeth with ECR. 


\section{Chapter III}

\section{Materials and Methods}

IN VITRO

This research was approved by the West Virginia University Institutional Review Board (WVU Protocol \#: 1909715997). Forty-eight extracted permanent human mandibular anterior teeth were selected from West Virginia University’s Tooth Repository. The samples were inspected for defects under an operating microscope (Global Surgical, St. Louis, MO, USA) and radiographed both buccolingually and mesiodistally to ensure only samples free of carious lesions, cracks, or restorations were included (Figure 1).
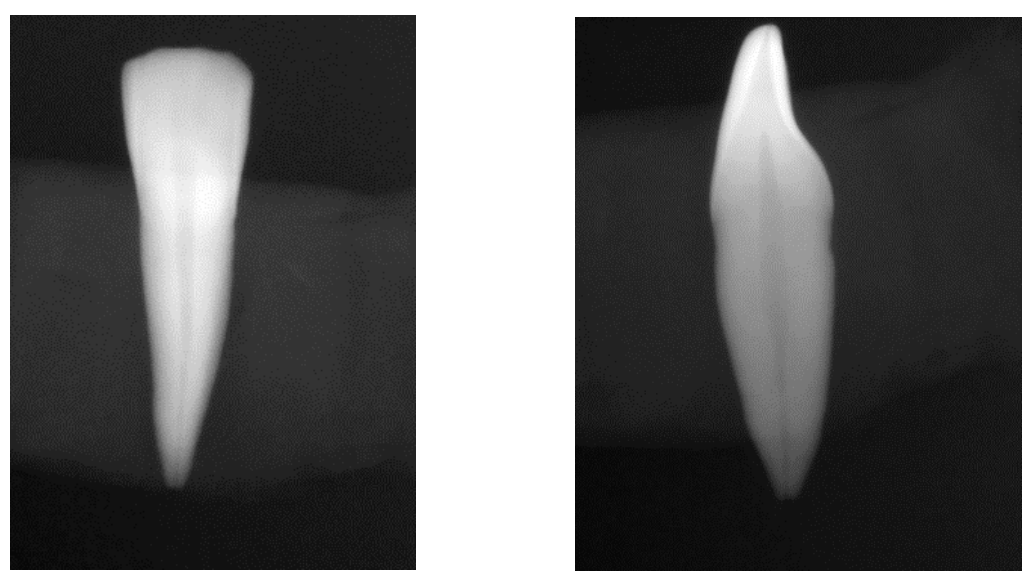

Figure 1. Samples radiographed in a buccolingual and mesiodistal orientation to examine for defects.

The teeth were measured using a digital caliper at the cementoenamel junction for buccolingual and mesiodistal widths. The tooth length was measured from the incisal edge to the apex. To ensure the use of specimens with comparable dimensions, teeth with more than $25 \%$ 
from the mean dimension value were excluded (28). The samples were held in a solution of 2 parts $8.25 \%$ sodium hypochlorite $(\mathrm{NaOCl}), 3$ parts glycerin, and 5 parts water in the repository and were transferred to a saline solution until use. The teeth were randomly divided into four groups (Figure 2) as follows:

Group 1: Negative control (NC): sound extracted teeth

Group 2: Positive control (PC): ECR cavity unrestored

Group 3: Fiber post (FP): ECR cavity restored, root canal therapy completed and reinforced with a fiber post

Group 4: Gutta percha (GP): ECR cavity restored and root canal therapy obturated with gutta percha
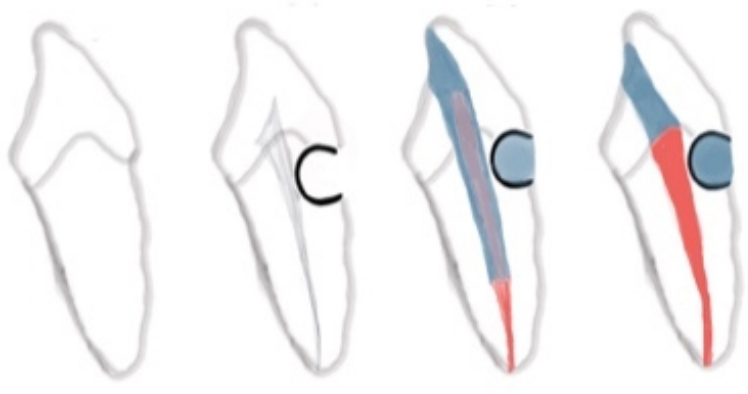

Figure 2. Diagram of representative samples from right to left: group 1, Negative control; group 2, Positive control; group 3, Fiber post; group 4, Gutta percha.

GP and FP were instrumented by accessing the pulp chamber through the lingual of their crowns (Figure 3). A no. 10 stainless steel hand file was inserted into the canal until the file was visible at the apical foramen and the canal length was measured using the incisal edge as a reference 
point. Working length was established by subtracting $0.5 \mathrm{~mm}$ from the determined canal length. The root canals were instrumented to a size \#30/.04 using Vortex Blue nickel titanium rotary files (Dentsply, Tulsa, OK, USA). During instrumentation the canals were irrigated with $8.25 \%$ $\mathrm{NaOCl}$. The smear layer was removed by irrigating with $17 \%$ ethylenediaminetetraacetic acid (EDTA) followed by $8.25 \% \mathrm{NaOCl}$. A final rinse of sterile saline was delivered to the canals before drying with paper points. The canals were obturated using a single gutta-percha cone and Endosequence Bioceramic Sealer (Brasseler USA, Savannah, GA) to the level of the cementoenamel junction. The access was restored in the GP group using dual-cure composite resin build-up material (Paracore, Coltene Whaledent, USA). In the FP group the gutta-percha was burned out using a heated plugger leaving $6 \mathrm{~mm}$ of gutta-percha in the apical third and a size 0 UniCore glass fiber post (Ultradent, Salt Lake City UT, USA) was cemented (Figure 4) using the same dual-cure composite resin build-up material (Paracore, Coltene), filling the canal space and access.

ECR cavities with a diameter of $2.9 \mathrm{~mm}$ were created at the CEJ in groups PC, GP, and FP (Figure 5) using the same round diamond bur (5801.31.029, Brasseler USA, Savannah, GA). The ECR cavities of groups GP and FP were restored using a resin-modified glass ionomer material (GC Fuji II, GC America). Figure 6 shows radiographs of completed treatment in all four groups. After treatment, the teeth were mounted vertically in self-cure acrylic resin blocks at $2 \mathrm{~mm}$ apical to the CEJ in the NC group and at the apical portion of the ECR cavity in the PC, FP, and GP groups, to mimic bone level (Figure 7). A surveyor was used to position the teeth perpendicular to the floor to simulate tooth position of mandibular incisors in the mandible. In order to maintain hydration of the teeth, the mounted specimens were stored in a saline solution and taken out of the solution only when fracture testing was conducted. 


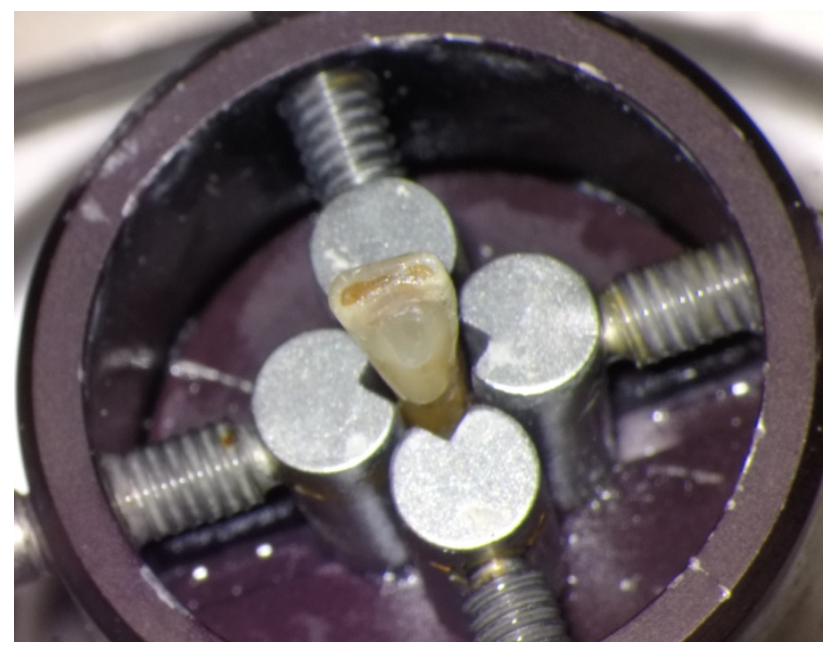

Figure 3. Mounting device used to hold specimen for access, instrumentation, and obturation.

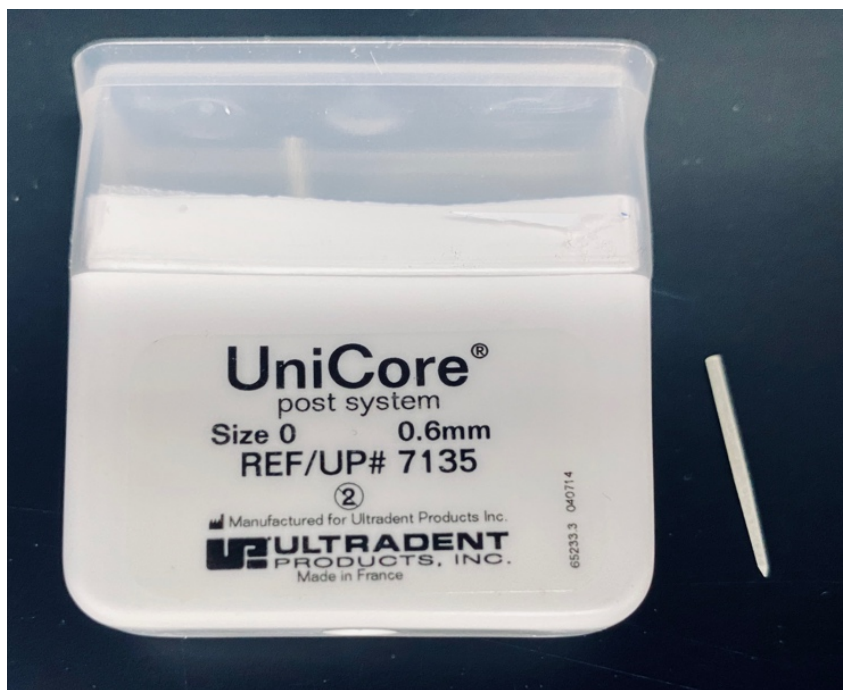

Figure 4. UniCore glass fiber post in a size 0. 


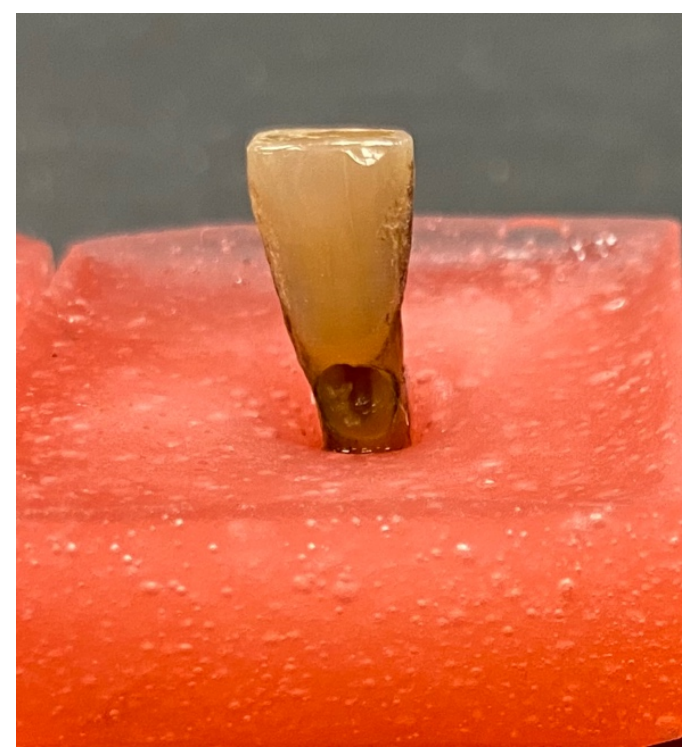

Figure 5. Specimen from Group 2, PC, with non-restored ECR cavity mounted in an acrylic block.

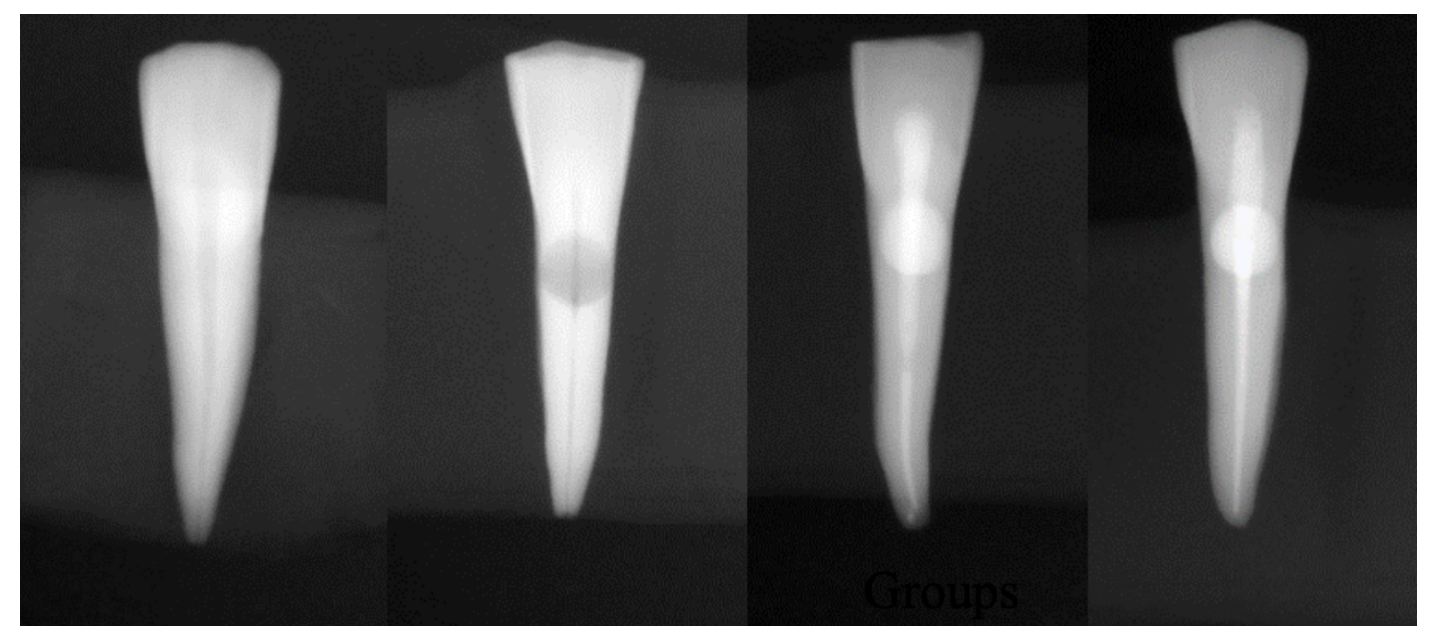

Figure 6: Radiographs of representative samples from right to left: group 1, Negative control; group 2, Positive control; group 3, Fiber post; group 4, Gutta percha. 


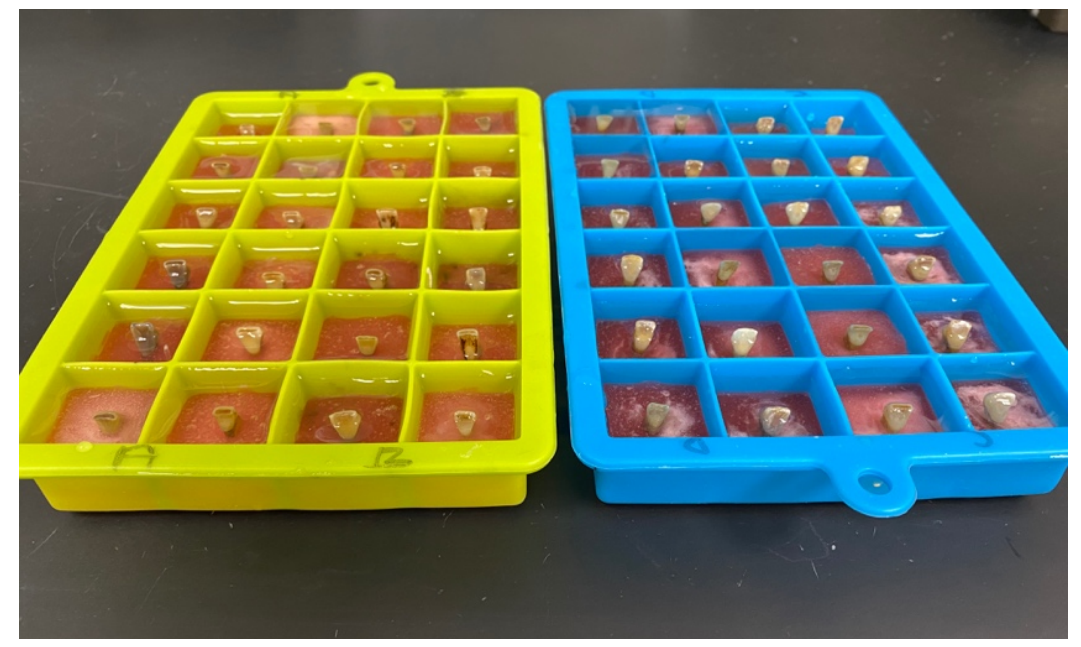

Figure 7. Teeth mounted in acrylic resin blocks.

\section{Fracture testing}

Fracture resistance testing was performed on an Instron machine (Instron, Norwood, MA, USA) using a compressive vertical load at a cross head speed of $0.5 \mathrm{~mm} / \mathrm{min}$ with a chisel shaped probe (28). The probe was applied at $6 \mathrm{~mm}$ from the incisal edge on the facial surface of each specimen at $90^{\circ}$ to the long axis of the tooth (Figure 8). The maximum load at which the samples fractured was recorded in newtons $(\mathrm{N})$. 

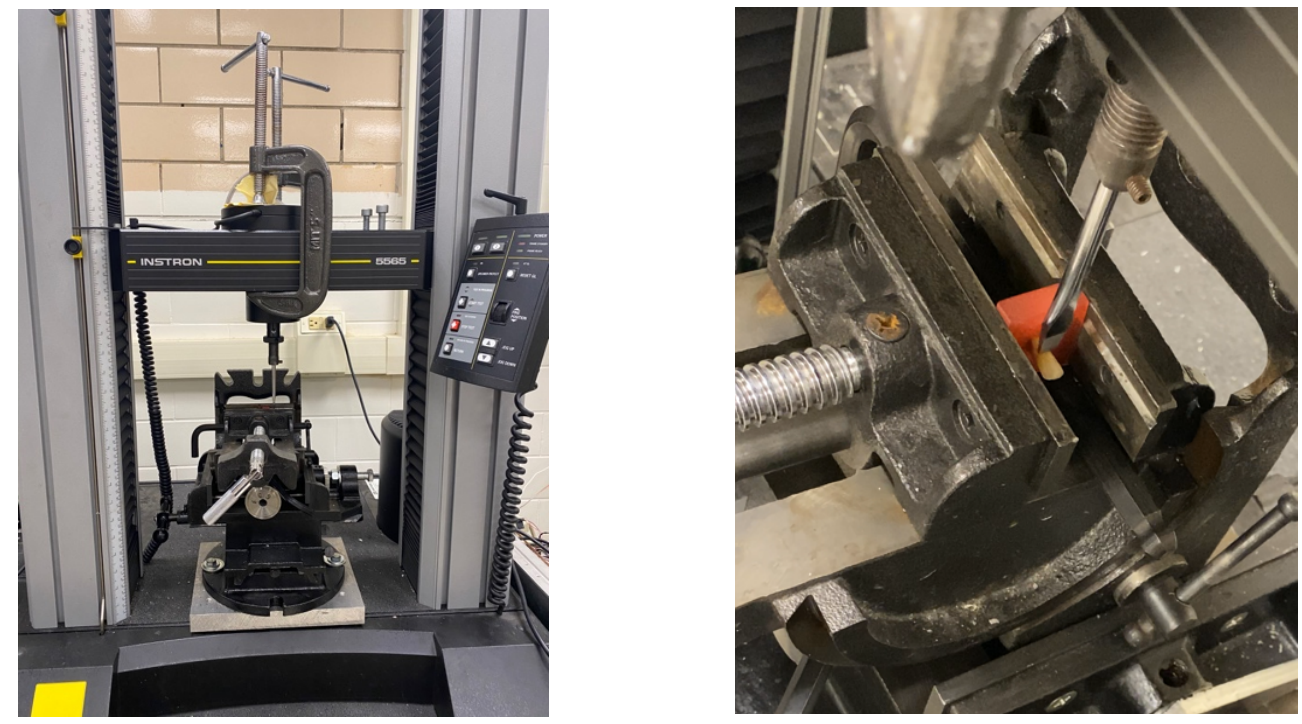

Figure 8. Instron machine with specimen mounted and ready for testing.

\section{Statistical analysis}

All statistical analysis was performed using SPSS software (IBM Corp, Armonk, NY). Data was analyzed using one-way analysis of variance (ANOVA) to compare the mean fracture resistance among the four groups, followed by the multiple comparison Tukey's post hoc test. A p-value of less than 0.05 was considered statistically significant.

\section{Failure pattern}

Each fractured sample was examined under a surgical microscope at $6.4 \mathrm{x}$ magnification (Global Surgical, St. Louis, MO) to record the location of the fracture. 


\section{Chapter IV}

\section{Results}

The mean fracture resistance and standard deviation values for each group are presented in Table 1. The negative control group had the highest mean fracture resistance of $422.38 \mathrm{~N}$. The mean fracture resistance values of the remaining groups were similar, with the positive control having a mean value of $170.89 \mathrm{~N}$ and the fiber post and gutta percha group having values of 181.17 $\mathrm{N}$ and $180.3 \mathrm{~N}$, respectively. Figure 9 illustrates the mean fracture resistance values of each group. According to the analysis of variance, there was a significant difference in fracture resistance between the groups $(P=.00)$. The Tukey post hoc test revealed that the fracture resistance of the negative control group was significantly higher than the other experimental groups $(P<0.05)$. Table 2 displays the significant multiple comparisons between the negative group and groups 2 through 4 . There were no other significant differences found between any other groups.

After evaluating the failure pattern under the surgical microscope, it was found that each specimen fractured with a single horizontal or oblique fracture pattern, but the location of each fracture differed in some of the groups. In group 1, nine specimens fractured in the coronal third of the root (figure 10) and three specimens exhibited a coronal failure. All specimens of group 2 fractured at the inferior portion of the ECR cavity (figure 11), while all specimens in group three fractured in the root at the apical extent of the post. Figure 12 illustrates the failure pattern of the post group. The pattern of group 4 was similar to group 2 in that all specimens fractured at the inferior portion of the ECR cavity (Figure 13). 


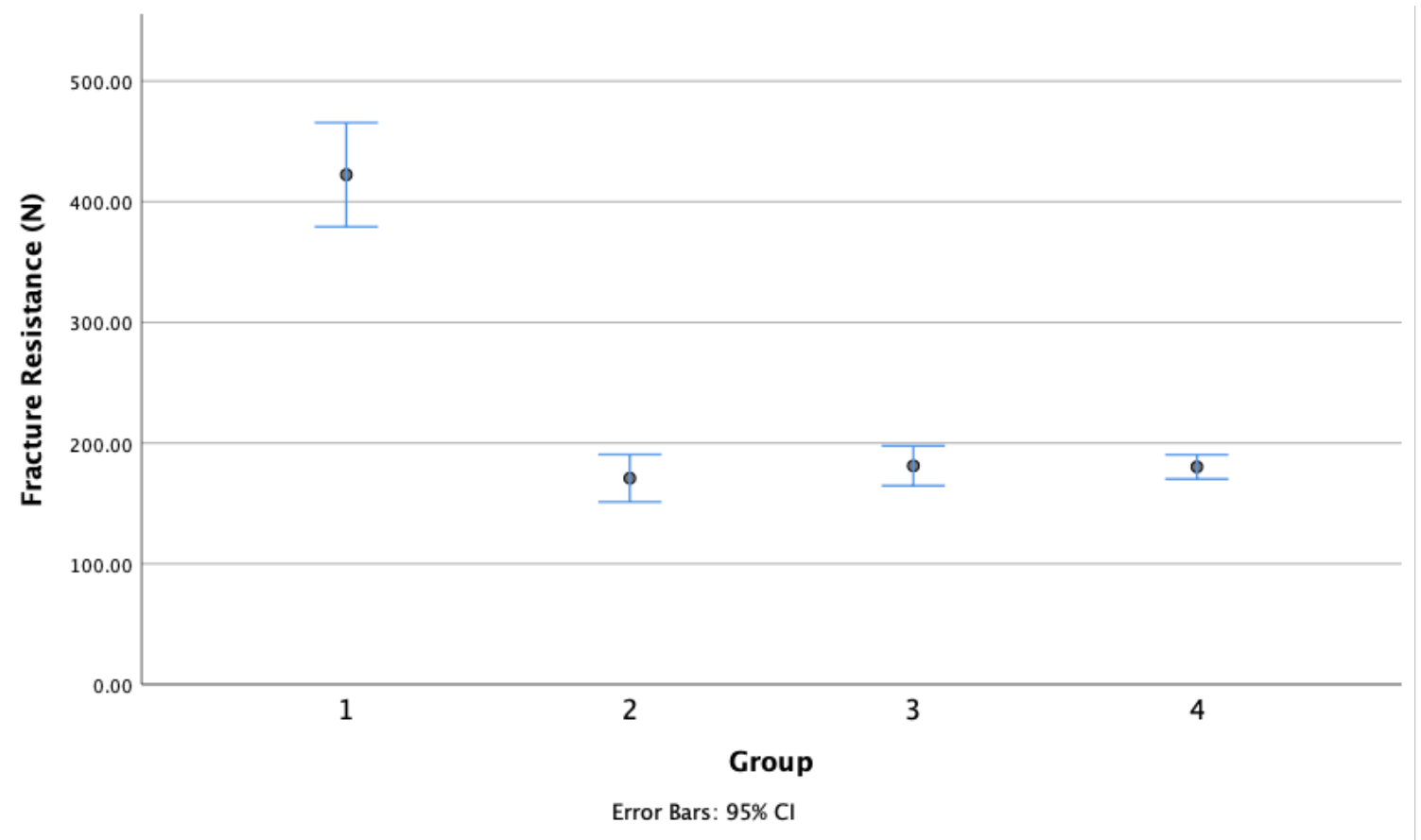

Figure 9. Comparison of mean fracture resistance $(\mathrm{N})$ of the experimental groups.

$\begin{array}{lccc}\text { Group } & \text { Number } & \text { Mean Fracture Resistance (N) } & \begin{array}{c}\text { Standard } \\ \text { Deviation }\end{array} \\ \text { Group 1. Negative control } & 12 & 422.38 & 67.85 \\ \text { Group 2. Positive control } & 12 & 170.89 & 30.95 \\ \text { Group 3. Fiber post } & 12 & 181.17 & 26.06 \\ \text { Group 4. Gutta percha } & 12 & 180.30 & 15.84\end{array}$

Table 1. Mean fracture resistance and standard deviation values of experimental groups. 


\begin{tabular}{|c|c|c|c|}
\hline Group & $\begin{array}{l}\text { Mean } \\
\text { Difference (N) }\end{array}$ & $\begin{array}{l}\text { 95\% Confidence } \\
\text { Interval }\end{array}$ & P-value \\
\hline $1-2$ & 251.50 & $207.58-295.41$ & $*$ \\
\hline $1-3$ & 241.21 & $197.30-285.12$ & $*$ \\
\hline $1-4$ & 242.08 & $198.16-285.99$ & $*$ \\
\hline \multicolumn{2}{|r|}{$*$ P-value of $<\mathbf{0 . 0 5}$ was considered significant. } \\
\hline
\end{tabular}

Table 2. Statistically significant results of multiple comparisons between groups.

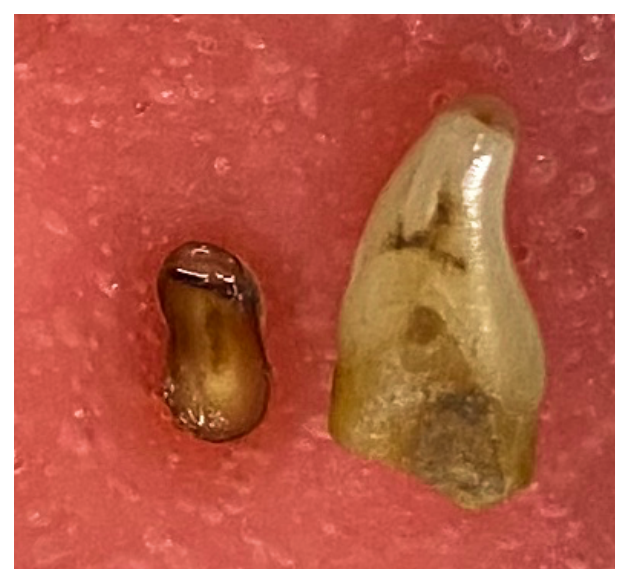

Figure 10. Specimen from Group 1 presenting with a fracture at the coronal third of the root. 


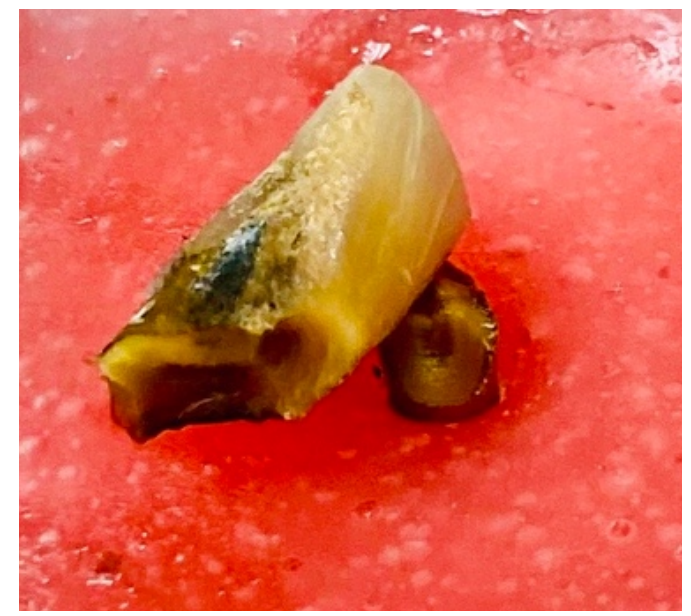

Figure 11. Group 2 specimen presenting with a fracture at the inferior portion of the ECR cavity.

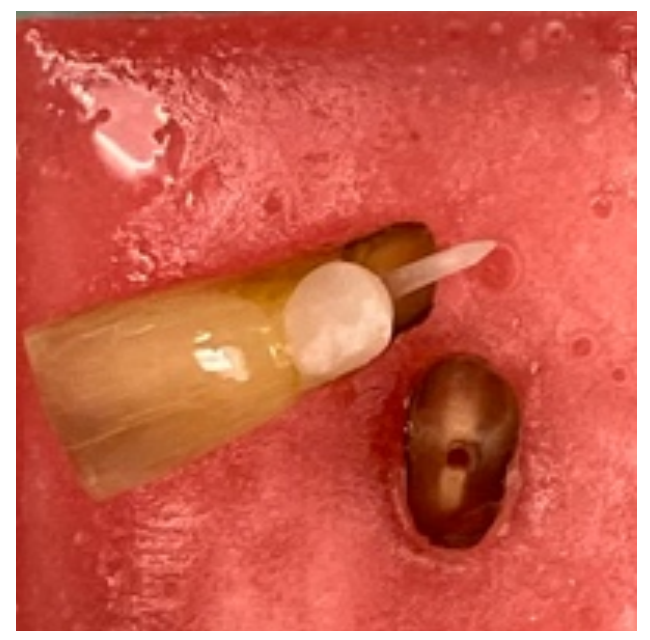

Figure 12. Group 3 specimen presenting with an oblique fracture at the apical portion of the fiber post. 


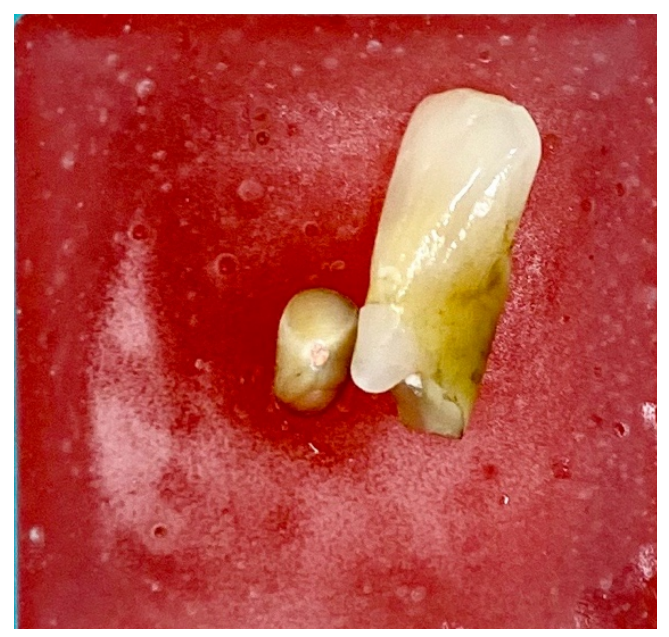

Figure 13. Group 4 specimen presenting with a fracture inferior to the ECR repair. 


\section{Discussion}

This study was completed in-vitro with simulated ECR defects that were standardized by using the same round bur below the CEJ of every tooth, but this testing method has its limitations in that it may not fully replicate in-vivo ECR irregular lesions. Mandibular central incisors were selected instead of maxillary incisors, the most frequent tooth affected by ECR, as mandibular central incisors were found to have less defects and prior restorations (12). Additionally, teeth can vary greatly in dimensions from one person to another; in order to limit this variation teeth were only included that met the set standardized dimension criteria.

Recently, clinicians have been noticing an increase in teeth presenting with ECR, which may be due to the more frequent use of CBCT technology. As the number of teeth with ECR rise, this type of resorption is being treated more often and we have seen more case reports of these treatments being published $(23,40)$. However, treating ECR can be very challenging when the resorptive process has destroyed an extensive amount of tooth structure. The subgingival location and often times circumferential spread of the resorption not only makes the lesion difficult to access but the substantial loss of tooth structure may affect the tooth's structural integrity. Thus, a treatment plan that addresses the endodontic, periodontic, and restorative needs for the tooth is essential. This study was conducted to aid clinicians in formulating a restorative treatment plan for teeth with ECR by comparing fracture resistance of untreated and treated ECR defects with and without intraradicular post reinforcement.

Although this is the first investigation to evaluate the fracture resistance in teeth with ECR, previous studies have tested fracture resistance in teeth with other types of pathologic loss of radicular dentin such as immature apices and teeth with internal root resorption to which we can compare our study. These studies also looked at reinforcing the loss of dentin with various 
intracanal materials including post placement $(28,38,41)$. As we make a comparison to immature teeth it is important to note that unlike immature teeth that lack thickened dentinal walls throughout the length of the root, ECR defects caused loss of dentin in the coronal third of the root.

The present study concluded that both unrestored and restored ECR groups were found to have a significant decrease in fracture resistance when compared to a virgin tooth, indicating that the resultant loss of tooth structure from the ECR lesion is responsible. This finding supports previous studies that have reported missing tooth structure as the principle contributor to the loss of tooth strength $(3,8)$. Similar observations were made by Seto et al $(28)$ who found that simulated immature anterior teeth with missing radicular tooth structure, regardless of the restorative material used, had a lower fracture resistance when compared to an intact virgin tooth. To guarantee no further dentin was lost other than the ECR lesion and the endodontic access, a passive fiber post was chosen to fit the canal space without post preparation. It was found that neither placing a fiber post or obturating the canal space with gutta percha were able to increase the fracture resistance of teeth presenting with ECR. While the mean fracture resistance of the fiber post and gutta percha groups were slightly higher than the positive control group, the differences were not statically significant. These findings are in agreement with Jamshidi et al (42) who found that placing a fiber post in simulated immature anterior teeth did not increase their fracture strength.

Dissimilar to the results of this investigation, several researchers have found that placing a post in simulated immature teeth can increase fracture resistance $(28,37,43)$. Schmoldt et al (44) showed that immature teeth with thin dentin walls were significantly strengthened when a fiber post was placed. While Seto et al (28) concluded that restoring immature teeth with a fiber 
post or a dual-cure composite were both able to significantly increase the fracture resistance of the weakened roots. The increase in fracture resistance by placing a fiber post is attributed to the distribution of force and the similar modulus of elasticity of fiber posts and dentin (34).

It has been reported that placing a fiber post allowed for a more favorable and restorable fracture, but this was not the case in this experiment (27). When analyzed, the only restorable failure pattern was detected in the negative control group. The similar failure patterns found in the positive control and GP group demonstrated that the weakest point of the root when ECR was present was the inferior boarder of the lesion, where the oblique fracture point was located. Placing a post in teeth with ECR caused the fracture location to alter and present at the end of the post in the apical third of the root. Consequently, Groups 2, 3, and 4 fractured with catastrophic root failures. 


\section{Chapter IV}

\section{Conclusions}

Within the limitations of this laboratory investigation, it can be concluded that ECR causes teeth to be weaker and have the potential to fracture at a lower force than a tooth without ECR. Restoring ECR teeth with and without a post had similar fracture resistances. Thus, placing a fiber post is not necessary as it will not increase fracture resistance of teeth with simulated ECR. Based on these findings the null hypothesis could not be rejected. To validate these in-vitro results future prospective clinical trials should be conducted that evaluate failure rates of teeth with ECR that have been restored with and without intraradicular post reinforcement. 


\section{Works Cited}

1 Mavridou A, Hauben E, Wevers M, Schepers E, Bergmans L, Lambrechts P. Understanding External Cervical Resorption in Vital Teeth. J Endod 2016;42(12):173751 .

2 Schwartz R, Robbins J, Rindler E. Management of invasive cervical resorption: observations from three private practices and a report of three cases. J Endod 2010;36(10):1721-30.

3 Kishen A. Mechanisms and risk factors for fracture predilection in endodontically treated teeth. Endod Top 2006;13(1):57-83.

4 Kishen A, Asundi A. Photomechanical investigations on post endodontically rehabilitated teeth. J Biomed Opt 2002;7(2):262-70.

5 Cvek M. Prognosis of luxated non-vital maxillary incisors treated with calcium hydroxide and filled with gutta-percha. A retrospective clinical study. Dent Traumatol 1992;8(2):4555.

6 Fennis W, Kuijs R, Kreulen C, Roeters F, Creugers N, Burgersdijk R. A survey of cusp fractures in a population of general dental practices. Int J Prosthodont 2002;15(6):559-63.

7 Goodacre C, Spolnik K. The prosthodontic management of endodontically treated teeth: a literature review. Part I. Success and failure data, treatment concepts. J Prosthodont 1994;3(4):243-50.

8 Reeh E, Messer H, Douglas W. Reduction in Tooth Stiffness as a Result of Endodontic and Restorative Procedures. J Endod 1989;15(11):512-6.

9 Heithersay G. Invasive cervical resorption following trauma. Aust Endod J 1999;25(2):79-85.

10 Heithersay G. Clinical, radiologic, and histopathologic features of invasive cervical resorption. Quintessence Int 1999;30:27-37.

11 Heithersay G. Endodontics Invasive cervical resorption: An analysis of potential predisposing factors. Quintessence Int 1999;30:83-95.

12 Mavridou A, Bergmans L, Barendregt D, Lambrechts P. Descriptive Analysis of Factors Associated with External Cervical Resorption. J Endod 2017;43(10):1602-10.

13 von Arx T, Schawalder P, Ackermann M, Bosshardt D. Human and Feline Invasive Cervical Resorptions: The Missing Link?-Presentation of Four Cases. J Endod 2009;35(6):904-13.

14 Gold S, Hasselgren G. Peripheral inflammatory root resorption. A review of the literature with case reports. J Clin Periodontol 1992;19(8):523-34.

15 Neuvald L, Consolaro A. Cementoenamel Junction: Microscopic Analysis and External Cervical Resorption. J Endod 2000;26(9):503-8.

16 Patel S, Mavridou A M, Lambrechts P, Saberi N. External cervical resorption-part 1: histopathology, distribution and presentation. Int Endod J 2018;51(11):1205-23.

17 Bergmans L, Van Cleynenbreugel J, Verbeken E, Wevers M, Van Meerbeek B, Lambrechts P. Cervical external root resorption in vital teeth: X-ray microfocustomographical and histopathological case study. J Clin Periodontol 2002;29(6):580-5.

18 Patel S, Kanagasingam S, Pitt Ford T. External Cervical Resorption: A Review. J Endod 2009;35(5):616-25.

19 Fayad M, Nair M, Levin M, et al. AAE and AAOMR Joint Position Statement Use of Cone Beam Computed Tomography in Endodontics 2015 Update. Oral Surg Oral Med 
Oral Pathol Oral Radiol 2015;120(4):508-12.

20 Heithersay G. Treatment of invasive cervical resorption: an analysis of results using topical application of trichloracetic acid, curettage, and restoration. Quintessence Int 1999;30(2):96-110.

21 Gupta S, Saxena P, Pant V, Pant A. Adhesion and biologic behavior of human periodontal fibroblast cells to resin ionomer Geristore: A comparative analysis. Dent Traumatol 2013;29(5):389-93.

22 Martins T, Bosco A, Nóbrega F, Nagata M, Garcia V, Fucini S. Periodontal Tissue Response to Coverage of Root Cavities Restored With Resin Materials: A Histomorphometric Study in Dogs. J Periodontol 2007;78(6):1075-82.

23 Asgary S, Nourzadeh M, Verma P, Hicks L, Nosrat A. Vital Pulp Therapy as a Conservative Approach for Management of Invasive Cervical Root Resorption: A Case Series. J Endod 2019;45(9):1161-7.

24 Carter J, Sorensen S, Johnson R, Teitelbaum R, Levine M. Punch shear testing of extracted vital and endodontically treated teeth. J Biomech 1983;16(10):841-8.

25 Schwartz R, Robbins J. Post Placement and Restoration of Endodontically Treated Teeth: A Literature Review. J Endod 2004;30(5):289-301.

26 Sedgley C, Messer H. Are Endodontically Treated Teeth more Brittle? J Endod 1992;18(7):332-5.

27 Akkayan B, Gülmez T. Resistance to fracture of endodontically treated teeth restored with different post systems. J Prosthet Dent 2002;87(4):431-7.

28 Seto B, Chung K, Johnson J, Paranjpe A. Fracture resistance of simulated immature maxillary anterior teeth restored with fiber posts and composite to varying depths. Dent Traumatol 2013;29(5):394-8.

29 Soares C, Soares P, Santos-Filho P, Castro C, Magalhaes D, Versluis A. The Influence of Cavity Design and Glass Fiber Posts on Biomechanical Behavior of Endodontically Treated Premolars. J Endod 2008;34(8):1015-9.

30 Ferrari M, Cagidiaco M, Grandini S, De Sanctis M, Goracci C. Post Placement Affects Survival of Endodontically Treated Premolars. J Dent Res 2007;86(8):729-34.

31 Guzy G, Nicholls J. In vitro comparison of intact endodntically treated teeth with and without endo-post reinforcement. J Prosthet Dent 1979;42(1):39-44.

32 Fokkinga W, Le Bell A, Kreulen C, Lassila L, Vallittu P, Creugers N. Ex vivo fracture resistance of direct resin composite complete crowns with and without posts on maxillary premolars. Int Endod J 2005;38(4):230-7.

33 Heydecke G, Butz F, Strub J. Fracture strength and survival rate of endodontically treated maxillary incisors with approximal cavities after restoration with different post and core systems: An in-vitro study. J Dent 2001;29(6):427-33.

34 Al-Omiri M, Mahmoud A, Rayyan M, Abu-Hammad O. Fracture Resistance of Teeth Restored with Post-retained Restorations: An Overview. J Endod 2010;36(9):1439-49.

35 Sidoli G, King P, Setchell D. An in vitro evaluation of a carbon fiber-based post and core system. J Prosthet Dent 1997;78(1):5-9.

36 Al-Hazaimeh N, Gutteridge D. An in vitro study into the effect of the ferrule preparation on the fracture resistance of crowned teeth incorporating prefabricated post and composite core restorations. Int Endod J 2001;34(1):40-6.

37 Topçuoğlu H, Kesİm B, Tuncay Ö, Demİrbuga S, Topçuoğlu G. The effect of various backfilling techniques on the fracture resistance of simulated immature teeth performed 
apical plug with Biodentine. Int J Paediatr Dent 2015;25(4):248-54.

38 Tuna E, Dinçol M, Gençay K, Aktören O. Fracture resistance of immature teeth filled with BioAggregate, mineral trioxide aggregate and calcium hydroxide. Dent Traumatol 2011;27(3):174-8.

39 Maddalone M, Gagliani M, Citterio C, Karanxha L, Pellegatta A, Del Fabbro M. Prevalence of vertical root fractures in teeth planned for apical surgery. A retrospective cohort study. Int Endod J 2018;51(9):969-74.

40 Krug R, Soliman S, Krastl G. Intentional Replantation with an Atraumatic Extraction System in Teeth with Extensive Cervical Resorption. J Endod 2019;45(11):1390-6.

41 Aktemur S, Uzunoglu E, Sungur D, Tek V. Fracture Resistance of Teeth with Simulated Perforating Internal Resorption Cavities Repaired with Different Calcium Silicate-based Cements and Backfilling Materials. J Endod 2018;44(5):860-3.

42 Jamshidi D, Homayouni H, Moradi NM, Shahabi S, Arvin A, Omidi BR. Impact and Fracture Strength of Simulated Immature Teeth Treated with Mineral Trioxide Aggregate Apical Plug and Fiber Post Versus Revascularization. J Endod 2018;44(12):1878-82.

43 Linsuwanont P, Kulvitit S, Santiwong B. Reinforcement of Simulated Immature Permanent Teeth after Mineral Trioxide Aggregate Apexification. J Endod 2018;44(1):163-7.

44 Schmoldt S, Kirkpatrick T, Rutledge R, Yaccino J. Reinforcement of simulated immature roots restored with composite resin, mineral trioxide aggregate, gutta-percha, or a fiber post after thermocycling. J Endod 2011;37(10):1390-3. 


\section{Appendix}

Data Results

\begin{tabular}{|c|c|c|}
\hline Group & Tooth \# & $\begin{array}{l}\text { Fracture } \\
\text { Resistance } \\
\text { (Newtons) }\end{array}$ \\
\hline 1 & 1 & 410.52 \\
\hline 1 & 2 & 598.12 \\
\hline 1 & 3 & 471.17 \\
\hline 1 & 4 & 384.65 \\
\hline 1 & 5 & 430.62 \\
\hline 1 & 6 & 380.99 \\
\hline 1 & 7 & 363.58 \\
\hline 1 & 8 & 326.25 \\
\hline 1 & 9 & 410.48 \\
\hline 1 & 10 & 456.08 \\
\hline 1 & 11 & 414.85 \\
\hline 1 & 12 & 421.23 \\
\hline 2 & 13 & 187.63 \\
\hline 2 & 14 & 121.54 \\
\hline 2 & 15 & 203.99 \\
\hline 2 & 16 & 137.98 \\
\hline 2 & 17 & 176.24 \\
\hline
\end{tabular}




\begin{tabular}{|c|c|c|}
\hline 2 & 18 & 190.00 \\
\hline 2 & 19 & 204.13 \\
\hline 2 & 20 & 183.62 \\
\hline 2 & 21 & 151.97 \\
\hline 2 & 22 & 180.52 \\
\hline 2 & 23 & 195.96 \\
\hline 2 & 24 & 117.02 \\
\hline 3 & 25 & 174.52 \\
\hline 3 & 26 & 196.69 \\
\hline 3 & 27 & 221.18 \\
\hline 3 & 28 & 168.73 \\
\hline 3 & 29 & 143.82 \\
\hline 3 & 30 & 124.56 \\
\hline 3 & 31 & 190.81 \\
\hline 3 & 32 & 201.73 \\
\hline 3 & 33 & 189.89 \\
\hline 3 & 34 & 192.62 \\
\hline 3 & 35 & 178.29 \\
\hline 3 & 36 & 191.22 \\
\hline 4 & 37 & 164.6 \\
\hline 4 & 38 & 209.68 \\
\hline 4 & 39 & 178.17 \\
\hline 4 & 40 & 180.73 \\
\hline
\end{tabular}




\begin{tabular}{|c|c|c|}
\hline 4 & 41 & 164.65 \\
\hline 4 & 42 & 167.81 \\
\hline 4 & 43 & 171.95 \\
\hline 4 & 44 & 195.07 \\
\hline 4 & 45 & 198.9 \\
\hline 4 & 46 & 184.53 \\
\hline 4 & 47 & 157.83 \\
\hline 4 & 48 & 189.72 \\
\hline
\end{tabular}

